\title{
Evaluation of Antimicrobial Activity of Aqueous and Hydro-Alcoholic Curcuma Longa Extracts against Endodontic Pathogens
}

\author{
Prof. (Dr) Mithra N Hegde ${ }^{1}$, Dr. Shishir Shetty ${ }^{2}$, Dr. Mahalaxmi Yelapure ${ }^{3}$, Amit Patil ${ }^{4}$ \\ ${ }^{1,2,3}$ (Department of Conservative Dentistry and Endodontics, A B Shetty Memorial Institute of Dental Sciences, Nitte \\ University, Mangalore, India.) \\ ${ }^{4}$ (Department of Pharmaceutics, NGSM Institute of Pharmaceutical Sciences, Nitte University, Mangalore, India.)
}

\begin{abstract}
The most commonly isolated bacteria from endodontically infected teeth are anaerobic, especially black-pigmented gram negative organisms. However, facultative microorganisms such as Enterococcus faecalis, aerobes like Staphylococcus aureus, and yeasts like Candida albicans are considered by many to be the most resistant species, and possible causes of root canal treatment failure. Irrigating solutions and intracanal medicaments are required to eradicate microorganisms, and over a period of time, a variety of chemicals have been introduced. The alarming incidence of antibiotic resistance amongst the microbes, has led to the search of alternative antimicrobial drugs from medicinal plants to treat these infections. Curcuma longa (turmeric) belonging to the Zingiberaeceae family, has been used for thousands of years as a flavouring agent, a medicinal herb, and a dyeing agent. Owing to its antimicrobial properties, it can prove to be useful in endodontics as well. Therefore; in the present study, aqueous and hydro-alcoholic extracts of the roots of Curcuma longa rhizome were prepared and solutions of different concentrations of the extracts were made. Antimicrobial susceptibility tests were performed using the agar well diffusion method. The Minimum inhibitory concentration (MIC) and the Minimum bactericidal concentration (MBC) were calculated. 2.3\% sodium hypochlorite solution was used as the positive control. Both extracts showed good antimicrobial properties against the endodontic pathogens. Hence, its future use as an endodontic irrigant or medicament should be considered and further evaluated.
\end{abstract}

Keywords: Curcuma longa, aqueous extract, hydro-alcoholic extract, endodontic pathogens, antimicrobial activity.

\section{INTRODUCTION}

One of the primary objectives of endodontic therapy is the microbial reduction or their elimination, to promote the normal healing and reestablishment of the health of the periradicular tissues. Mechanical instrumentation cannot sufficiently disinfect root canals and hence irrigating solutions and intracanal medicaments are required to eradicate microorganisms. Over a period of time, a variety of chemicals have been introduced. [1]

An endodontic irrigant/ medicament should ideally exhibit powerful antimicrobial activity, disinfect the root canal space, and have no cytotoxic effects on periradicular tissues.

Sodium hypochlorite, the commonly used endodontic irrigant, has many potential properties; but has a cytotoxic effect when injected into the periapical tissues. It is also known to produce allergic reactions; a foul smell and taste, tendency to bleach clothes and corrosive potential. [2] Studies have also shown the resistance of Enterococcus faecalis to it.

Therefore, an equally effective and a safe irrigant/ intracanal medicament is desirable.

Currently, most bacteria isolated from endodontically infected teeth are anaerobic, especially black-pigmented gram negative organisms. However, facultative microorganisms such as Enterococcus faecalis, aerobes like Staphylococcus aureus, and even Candida albicans are considered to be the most resistant species, and one of the possible causes of root canal treatment failure. [3]

Antimicrobial agents are many a time associated with adverse effects on the host like, hypersensitivity, immune suppression and allergic reactions. Also, the continuous evolution of bacterial resistance to currently available antimicrobial agents has necessitated the search for novel and effective antimicrobial compounds from alternative and natural sources like plants and herbs.[4]

According to World Health Organization (WHO) more than $80 \%$ of the world's population relies on traditional medicine for their primary healthcare needs. Use of herbal medicines in Asia represents a long history of human 
interactions with the environment. Plants used in traditional medicine contain a wide range of ingredients that can be used to treat chronic as well as infectious diseases. [5]

Curcuma longa (turmeric) belonging to the Zingiberaeceae family, has been used for thousands of years as a flavouring agent, a medicinal herb, and a dyeing agent. Ancient Indian medicine has touted Curcuma longa as a herb with the ability to provide glow and luster to the skin as well as vigor and vitality to the entire body. Since it has antimicrobial, antioxidant, astringent, and other useful properties, it can be quite useful in Dentistry as well. [6]

Various studies have shown the antimicrobial effects of extracts of roots of Curcuma longa on various microorganisms like Staphylococcus aureus, Staphylococcus epidermidis, Enterococcus faecalis, Escherichia coli, Klebsiella pneumonia, Candida albicans, and Candida kruseii.[7][8][9][10]

Considering the above mentioned factors, the present study was conducted to evaluate the antimicrobial activity of Curcuma longa extracts on endodontic pathogens.

\section{MATERIALS AND METHODS}

\section{II.1. COLLECTION AND AUTHENTIFICATION OF RHIZOMES}

Fresh rhizomes of Curcuma longa of analytical grade, grown organically without the use of any pesticides were collected (Shobha Vana, Moodbidri, Karnataka). Authentication of the rhizomes was done at the NGSM Institute of Pharmaceutical sciences, Mangalore.

\section{II.2. TEST ORGANISMS \\ Enterococcus faecalis (ATCC 29212) [ MicroBiologics, St. Cloud MN] \\ Staphylococcus aureus (ATCC 25923) [ MicroBiologics, St. Cloud MN] \\ Candida albicans (NTCC 3736) [ MicroBiologics, St. Cloud MN]}

III.3. MEDIA USED

Nutrient Broth [HiMedia laboratories pvt ltd, Mumbai]

Mueller Hinton Agar [HiMedia laboratories pvt ltd, Mumbai]

Sabouraud's Dextrose Agar [HiMedia laboratories pvt ltd, Mumbai]

\section{II.4. EXTRACT PREPARATION}

The rhizomes were washed with distilled water (B. K. Chemicals, Pune, India.) and dried. They were then cut into irregular large pieces and dried in an oven by tray drying process at a temperature of $45 \pm 5^{\circ} \mathrm{C}$ for a period of about $9-10$ days till they were completely moisture-free. The irregular large sized pieces were ground to form a coarse powder.

Maceration process of extraction was then performed on this coarse powder of the rhizomes. [11] 500 gms of coarsely ground powder of the Curcuma longa rhizomes was placed in two large glass chambers each. To one glass chamber 2500 $\mathrm{ml}$ of sterile distilled water was added to prepare the aqueous extract and to another one, approximately $1550 \mathrm{ml}$ of water and $850 \mathrm{ml}$ of ethanol (95\%) (Durga labs, Mangalore, India) was added in a 70:30 ratio of water and alcohol to get a hydro-alcoholic extract. Both the glass chambers were closed with a glass lid to prevent evaporation of the menstruum and this system was allowed to stand for 7 days with occasional stirring. The liquid i.e. the menstruum was then strained and the solid residue, called marc, was pressed to recover as much occluded solution as possible. The strained and expressed liquid thus obtained were mixed and clarified by filtration. The filtration was carried out in a beaker using a Whatman's filter paper no 1(Durga labs, Mangalore, India). $2000 \mathrm{ml}$ of menstruum was obtained which was stored in a refrigerator at $4^{\circ} \mathrm{C}$ in two beakers.

China dishes (Rotek instruments, Kerala, India) were used for evaporation of the menstruum. These china dishes containing the menstruum were placed on a water bath (Rotek instruments, Kerala, India). After evaporation of the menstruum a thick dark brown colored sticky mass was obtained as the aqueous extract and a yellowish brown colored sticky mass as the hydro-alcoholic extract. These extracts were stored in a dark colored pre-sterilized airtight container. The same procedure was performed for the remaining menstruum. It was then stored in a refrigerator at $4^{\circ} \mathrm{C}$ in a dark colored pre-sterilized airtight container until its further use.

\section{II.5. PREPARATION OF MICROBIAL INOCULA}

The density of selected organisms was adjusted equal to that of the $0.5 \mathrm{McF}$ arland standards $(1.5 \mathrm{x} 108 \mathrm{CFU} / \mathrm{ml}) \mathrm{by}$ adding 
them to nutrient broth for Staphylococcus aureus and Enterococcus faecalis; and Sabouraud's dextrose broth for Candida albicans. A 24 hour old culture was used for the preparation of bacterial suspension. McFarland standards were used as a reference to adjust the turbidity of microbial suspension so that the number of microorganisms would be within a given range.

\section{II.6. ANTIMICROBIAL SUSCEPTIBILITY TEST}

Agar well diffusion method was used to conduct the antimicrobial susceptibility test.[12] Four different concentrations of each of the prepared extracts were made using DMSO (Dimethyl Sulfoxide).The four concentrations were $1 \mathrm{~g} / \mathrm{ml}, 0.75$ $\mathrm{g} / \mathrm{ml}, 0.5 \mathrm{~g} / \mathrm{ml}$ and $0.25 \mathrm{~g} / \mathrm{ml}$.

A sterile cotton swab was dipped into the respective microbial suspensions and surplus removed by rotation of the swab against the sides of the tube above the fluid level. The agar media plates were inoculated with the respective organisms by even streaking of the swab over the entire surface of the plate three times, rotating the plate approximately 60 degrees after each application to ensure an even distribution of the inoculums. Finally, it was swabbed all around the edge of the agar surface. Wells of $8 \mathrm{~mm}$ size were made with sterile borer into agar plates containing the bacterial inoculums. $100 \mu \mathrm{l}$ volume of each of the plant extract prepared in four concentrations was dispensed into the wells of inoculated plates.

Sterilized distilled water and ethanol were used as a negative control which were introduced into the wells instead of plant extract. DMSO which was the solvent for preparation of different concentrations of the extract was used as a control for the solvent and was introduced into one well. $2.3 \%$ sodium hypochlorite was the positive control since it is the commonly used irrigant and has excellent antimicrobial activity against the above mentioned organisms.

The plates thus prepared were refrigerated for 60 minutes allowing the diffusion of the extract into the agar . After incubation for $24 \mathrm{hrs}$ at $37^{\mathrm{C}} \mathrm{C}$, the plates were observed. If antibacterial activity was present on the plates, it was indicated by an inhibition zone surrounding the well containing the extract. The zone of inhibition was measured and expressed in millimeters. Antibacterial activity was recorded if the zone of inhibition was greater than $8 \mathrm{~mm}$. The antibacterial activity results were expressed in terms of the diameter of zone of inhibition and $<9 \mathrm{~mm}$ zone was considered as inactive; $9-12 \mathrm{~mm}$ as partially active; while13-18mm as active and $>18 \mathrm{~mm}$ as very active.[13] The mean and standard deviation of the diameter of inhibition zones were calculated.

\section{II.7. DETERMINATION OF MINIMUM INHIBITORY CONCENTRATION (MIC)}

MIC is defined as the lowest concentration where no visible turbidity is observed in the test tube (bacteriostatic concentration). The broth dilution technique was utilized where the rhizome extracts were prepared to the highest concentration of $750 \mathrm{mg} / \mathrm{ml}$ (stock concentration) in DMSO and serially diluted (two-fold) to a working concentration ranging from $0.08 \mathrm{mg} / \mathrm{ml}$ to $750 \mathrm{mg} / \mathrm{ml}$ using Nutrient broth for Staphylococcus aureus and Enterococcus faecalis and Sabouraud's dextrose broth for Candida albicans. These test tubes were then inoculated with $0.1 \mathrm{ml}$ suspension of the test organisms. After 24 hours of incubation at $37^{\circ} \mathrm{C}$, the test tubes were observed for turbidity. The least concentration where no turbidity is observed was determined and noted as the minimum inhibitory concentration (MIC) value. [14][15]

\section{II.8. DETERMINATION OF MINIMUM BACTERIAL CONCENTRATION (MBC)}

The MBC is defined as the lowest concentration where no bacterial growth is observed (bactericidal concentration). This was determined from the broth dilution resulting from the MIC tubes by sub culturing to antimicrobial free agar. [14][15]

In this technique, the contents of the test tubes resulting from MIC were streaked using a sterile wire loop on agar plates free of bacteria and incubated at $37^{\circ} \mathrm{C}$ for 24 hours. The lowest concentration of each of the extract which showed no bacterial growth was noted and recorded as the MBC.

\section{RESULTS}

It was seen that both aqueous and hydro-alcoholic extracts of Curcuma longa rhizome showed antimicrobial activity. However the antimicrobial properties of aqueous extract were found to be better than the hydro-alcoholic extract. The aqueous extract of Curcuma longa showed good inhibitory activity against Staphylococcus aureus and Candida albicans.

The results presented in Table 1 reveal that $75 \%$ concentration showed the greatest zone of inhibition of $13 \mathrm{~mm}$ against Staphylococcus aureus and the 50\% concentration showed the best zone of inhibition of $15.66 \mathrm{~mm}$ against Candida albicans.

The $100 \%, 75 \%$ and $25 \%$ concentrations of the aqueous extract showed no inhibitory activity against Enterococcus faecalis; however $50 \%$ concentration showed mild activity with a zone of inhibition of $9 \mathrm{~mm}$.

$50 \%$ concentration hydro-alcoholic extract showed the maximum zone of inhibition of 11.66mm against Staphylococcus aureus and $11.33 \mathrm{~mm}$ against Candida albicans. It did not show any activity against Enterococcus faecalis.

The positive control i.e. 2.3\% Sodium hypochlorite showed the best zones of inhibition (Table 1).The negative controls, distilled water, ethanol and dimethyl sulfoxide (DMSO) did not show any inhibitory activity on the organisms. 
The MIC (Figure 1) of aqueous extract against Staphylococcus aureus and Enterococcus faecalis was $37.5 \%$ (375 $\mathrm{mg} / \mathrm{ml})$ and $19 \%(190 \mathrm{mg} / \mathrm{ml})$ for Candida albicans.

The hydro-alcoholic extract showed no MIC values for Enterococcus faecalis and Staphylococcus aureus; whereas it was $19 \%(190 \mathrm{mg} / \mathrm{ml})$ for Candida albicans.

The MBC (Figure 2) of aqueous extract for Staphylococcus aureus and Enterococcus faecalis was $75 \%$ (750mg/ml) and $37.5 \%(375 \mathrm{mg} / \mathrm{ml})$ for Candida albicans.

No MBC values could be seen for Staphylococcus aureus and Enterococcus faecalis with the hydro-alcoholic extract whereas it was $37.5 \%(375 \mathrm{mg} / \mathrm{ml})$ for Candida albicans.

\section{III.1. TABLES AND FIGURES}

Table 1.Antimicrobial activity of Curcuma longa extracts against endodontic pathogens. (Agar well diffusion method)

\begin{tabular}{|c|c|c|c|c|c|c|}
\hline \multirow{2}{*}{ S NO } & \multirow[t]{2}{*}{ EXTRACT } & \multicolumn{4}{|c|}{ Different Concentrations of the extracts in \% } & \multirow{2}{*}{$\begin{array}{l}\text { CONTROL 2.3\% } \\
\text { NaOCl }\end{array}$} \\
\hline & & $100 \%$ & $75 \%$ & $50 \%$ & $25 \%$ & \\
\hline \multicolumn{7}{|c|}{ ZONES OF INHIBITION AGAINST STAPHYLOCOCCUS AUREUS (ATCC 25923) in mm } \\
\hline 1 & AQUEOUS & $10.66 \pm 1.15$ & $13 \pm 1.00$ & $10.33 \pm 0.577$ & $8.66 \pm 1.154$ & $14 \pm 1.00$ \\
\hline 2 & $\begin{array}{l}\text { HYDRO- } \\
\text { ALCOHOLIC }\end{array}$ & $9 \pm 1.00$ & $9.33 \pm 1.527$ & $11.66 \pm 1.154$ & $10 \pm 1.00$ & \\
\hline \multicolumn{7}{|c|}{ ZONES OF INHIBITION AGAINST ENTEROCOCCUS FAECALIS (ATCC 29212) in mm } \\
\hline 1 & AQUEOUS & -- & $8.33 \pm 0.577$ & $9 \pm 1.00$ & -- & $11 \pm 1.00$ \\
\hline 2 & $\begin{array}{l}\text { HYDRO- } \\
\text { ALCOHOLIC }\end{array}$ & -- & -- & - & -- & \\
\hline \multicolumn{7}{|c|}{ ZONES OF INHIBITION AGAINST CANDIDA ALBICANS (NTCC 3736) in mm } \\
\hline 1 & AQUEOUS & $9.66 \pm 1.527$ & $12.33 \pm 0.577$ & $15.66 \pm 0.577$ & $12.66 \pm 1.154$ & $16 \pm 1.00$ \\
\hline 2 & $\begin{array}{l}\text { HYDRO- } \\
\text { ALCOHOLIC }\end{array}$ & $8.66 \pm 0.577$ & $9.33 \pm 1.527$ & $11.33 \pm 1.527$ & $10.33 \pm 1.527$ & \\
\hline
\end{tabular}

Values are means of three readings \pm SEM

$--\rightarrow$ No Activity 


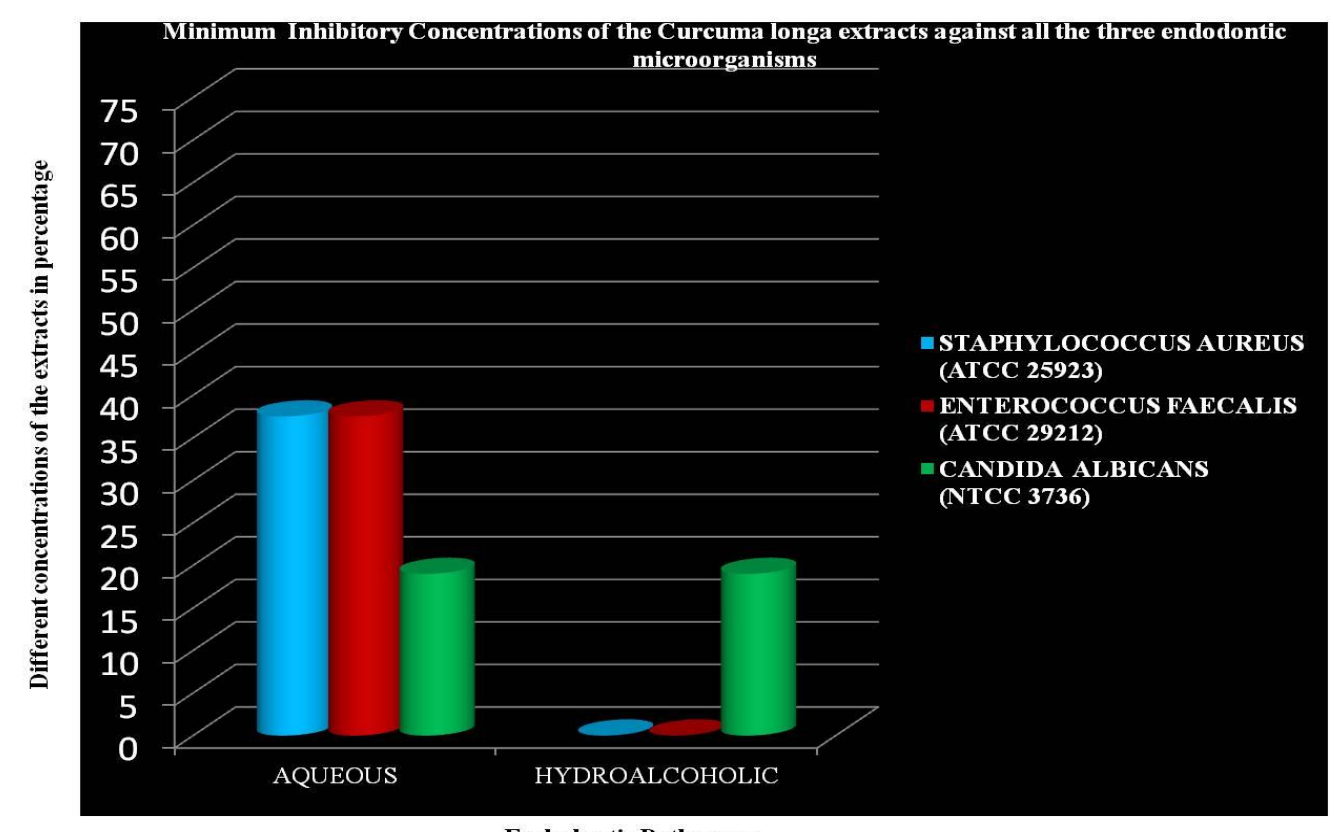

Endodontic Pathogens

Figure 1- Bar diagram showing Minimum Inhibitory Concentrations of the Curcuma longa extracts against the three endodontic pathogens.

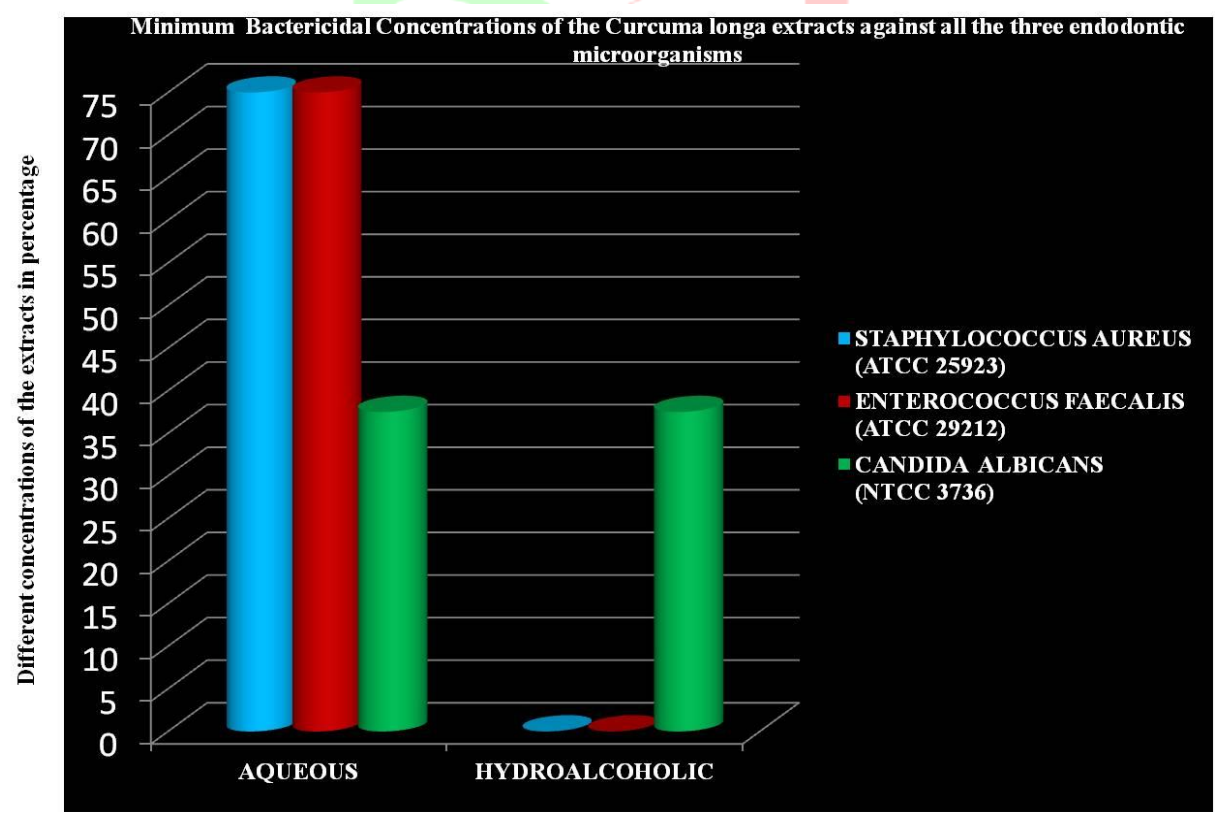

Endodontic Pathogens

Figure 2- Bar diagram showing Minimum Bactericidal Concentrations of the Curcuma longa extracts against the three endodontic pathogens.

\section{DISCUSSION}

An endodontic irrigant/medicament should ideally exhibit powerful antimicrobial activity, disinfect the root canal space, and have no cytotoxic effects on periradicular tissues, among various other properties required. Therefore, an equally effective and a safe irrigant/ medicament is desirable.[2]

Antimicrobial agents are many a time associated with adverse effects on the host like, hypersensitivity, immune suppression and allergic reactions. Also, the continuous evolution of bacterial resistance to currently available antimicrobial agents has necessitated the search for novel and effective antimicrobial compounds.

Various authors have shown the antimicrobial activity of Curcuma longa extracts against an array of pathogens. [7][8][9][10] In the present study, it was seen that both aqueous and hydro-alcoholic extracts of Curcuma longa rhizome showed antimicrobial activity against the tested endodontic pathogens. However the antimicrobial properties of aqueous 
extract were found to be better than the hydro-alcoholic extract. Successive extraction and isolation of botanical compounds from plant material is largely dependent on the type of solvent used in the extraction procedure. The traditional healers used water as the primary solvent.

The results in the present study were in contrast to the results reported by various authors stating that alcoholic extracts showed better antimicrobial properties than aqueous extracts.[9][16][17][18] However, the extract used in the present study was not completely alcoholic; it was hydro-alcoholic where the major solvent was water.

The aqueous extract of Curcuma longa showed good inhibitory activity against Staphylococcus aureus and Candida albicans in accordance to a study by N Niamsa (2009).[19] The greater concentrations did not show good inhibitory activity probably due to increased viscosity of the solution and hence lesser diffusion in the medium.

The hydro-alcoholic extract of Curcuma longa also showed inhibitory activity against Staphylococcus aureus and Candida albicans. This was in accordance with the results reported by Ungphaiboon et al (2005).[17] The greatest zone of inhibition of hydro-alcoholic extract was shown by 50\% concentration; $11.66 \mathrm{~mm}$ and $11.33 \mathrm{~mm}$ against Staphylococcus aureus and Candida albicans respectively. No inhibition of Enterococcus faecalis was seen.

None of the concentrations matched the zone of inhibition of $2.3 \%$ sodium hypochlorite, which was the positive control; however $50 \%$ concentration of aqueous extract showed equivalent zone of inhibition of $15.66 \mathrm{~mm}$ compared to $16 \mathrm{~mm}$ seen with that of control.

MIC was determined by the Vollekova et al (2001) method[14];later modified by Usman et al (2007).[15] The MIC (Minimum inhibitory concentration) of aqueous extract against Staphylococcus aureus, Enterococcus faecalis and Candida albicans were in the range of $19 \%-37.5 \%(190-375 \mathrm{mg} / \mathrm{ml})$.

The hydro-alcoholic extract showed no MIC values for Enterococcus faecalis and Staphylococcus aureus; whereas it was $19 \%(190 \mathrm{mg} / \mathrm{ml})$ for Candida albicans.

MBC was determined from the broth dilution resulting from the MIC tubes by sub culturing to antimicrobial free agar as described by Vollekova et al., (2001)[14] and Usman et al., (2007).[15] The MBC (Minimum bactericidal concentration) of aqueous extract for Staphylococcus aureus Enterococcus faecalis and Candida albicans were in the range of $37.5 \%-$ $75 \%(375-750 \mathrm{mg} / \mathrm{ml})$.

No MBC values could be seen for Staphylococcus aureus and Enterococcus faecalis with the hydro-alcoholic extract whereas it was $37.5 \%(375 \mathrm{mg} / \mathrm{ml})$ for Candida albicans.

\section{CONCLUSION}

Both the extracts of Curcuma longa showed antimicrobial activity against the tested organisms. The aqueous extract showed good results against Staphylococcus aureus and Candida albicans and mild activity against Enterococcus faecalis in comparison to the hydro-alcoholic extract. Also, both the extracts showed better antifungal activity than antibacterial activity. Thus; from the results obtained in the present study, it can be concluded that Curcuma longa extracts can prove to be potent antimicrobial agents against endodontic pathogens. Hence, its future use as an endodontic irrigant/medicament needs to be further studied.

\section{REFERENCES}

[1] Stephen Cohen, Kenneth Hargreaves. Pathways of the pulp 9th ed. (Mosby publishers, St Louis) 2007: 318-19.

[2] C. E. Radcliffe, L. Potouridou, R. Qureshi. Antimicrbial activity of varying concentrations of sodium hypochlorite on the endodontic microorganisms Actinomyces israelii, A. naeslundii, Candida albicans and Enterococcus faecalis. Int Endo J 2004; 37: 438-46.

[3] Morgana Eli Vianna, Brenda P. F. A. Gomes, Vanessa Bellocchio Berber. In vitro evaluation of the antimicrobial activity of chlorhexidine and sodium hypochlorite. O.Surg O.Med O.Patho 2004; 97: 7984.

[4] Rana Pratap Singh, D.A.Jain. Antibacterial activity of Alcoholic and Aqueous extracts of some Medicinal Plants. International Journal of Pharm Tech Research 2011 April-June; 3(2): 1103-1106.

[5] Diallo D., Hveem B., Mahmoud M.A., Betge G., Paulsen B.S. and Maiga A.. An ethnobotanical survey of herbal drugs of Gourma district. Mali.Pharmaceutical Biol. 1999; 37:80-91.

[6] Chaturvedi T P. Uses of turmeric in dentistry: An update. Indian J Dent Res 2009; 20: 107-9.

[7] Rambir Singh, Ramesh Chandra, Mridula Bose. Antibacterial activity of Curcuma longa rhizome extract 
on pathogenic bacteria. Current Science Sept 2002; 83(6): 737-40.

[8] N. Niamsa, C. Sittiwet. Antimicrobial activity of curcuma longa aqueous extract. J of Pharmacology and Toxicology 2009; 4(4):173-77.

[9] Kang-Ju Kim, Hyeon-Hee Yu, Se-Jeong Seo. Antibacterial activity of curcuma longa L. against Methicillin-resistant Staphylococcus aureus. Phytotherapy Research 2005 Sept.; (9) 7: 599-604.

[10] Park BS, Kim MR, Lee SE. Curcuma longa L. constituents inhibit sortase A and Staphylococcus aureus cell adhesion to fibronectin. J Agric Food Chem 2005 Nov 16; 53(23): 9005-9.

[11] Sukhdev Swami Handa, Suman Preet Singh Khanuja, Extraction Technologies for Medicinal and Aromatic Plants United Nations Industrial Development Organization and the International Centre for Science and High Technology, 2008.

[12] Mario Roberto Leonardo, Lea Assed Bezerra da Silva, Mario Tanomaru Filho, Kleber Cortes Bonifacio, Isabel Yoko Ito. In vitro evaluation of antimicrobial activity of sealers and pastes used in endodontics. Journal of Endod. 2000 July;.26( 7):391-394

[13] A. Junior, C. Zanil. Biological screening of Brazilian medicinal plants. Braz. J. Sci 2000; 95: 367-373.

[14] Vollekova A.D., Kostalova, R. Sochorova. Isoquinoline Alkaloids from Mahonia aquifolium stem bark is active against Malassezia Sp. Folia. Microbiol 2001; 46: 107-111.

[15] Usman H., F.I. Abdulrahman, A.H. Ladan. Phytochemical and Antimicrobial Evaluation of Tribulus terrestris L. (Zygophylaceae) Growing in Nigeria. Res. J. Bio. Sci. 2007; 2(3): 244-247.

[16] Nadia Gul, Talat Y, Mujahid, Nayyar Jehan. Studies on the Antibacterial effect of different fractions of Curcuma longa against Urinary tract infection isolates. P Journal of Biological Sciences2004; 7(12): 2055-60.

[17] Ungphaiboon S., Supavita. Study on antioxidant and antimicrobial activities of turmeric clear liquid soap for wound treatment of HIV patients. Songklanakarin J. Sci. Technol.2005; 27(2) : 569-578

[18] Ong-ard Lawhavinit, Pronchai Sincharoenpokai. Effects of Ethanol Turmeric (Curcuma longa Linn.) Extract Against Shrimp Pathogenic Vibrio spp. and on Growth Performance and Immune Status of White Shrimp (Litopenaeus vannamei). Kasetsart J. 2011; 45: 70 - 77.

[19] N. Niamsa, C. Sittiwet. Antimicrobial activity of curcuma longa aqueous extract. J of Pharmacology and Toxicology 2009; 4(4):173-77. 